\title{
CHEMICAL AND BIOLOGICAL CHARACTERIZATION OF VENOM OF THE ANT SOLENOPSIS XYLONI $\mathrm{McCOOK}$
}

\author{
By Murray S. Blum ${ }^{1}$, J. E. Roberts, Jr. ${ }^{2}$, and A. F. Novak ${ }^{3}$
}

The reaction of human beings to the sting of the indigenous southern fire ant (Solenopsis xyloni McCook) is in marked contrast to that produced by the sting of the closely related imported fire ant (Solenopsis saevissima [Fr. Smith]). Whereas the sting of $S$. saevissima is characterized by a painful edema and marked necrosis (Caro et al. [1957]), we have found that the sting of $S$. xyloni seldom results in more than a mild prurience. These facts strongly indicate that the venoms of these two species of Solenopsis differ chemically. The purpose of this present paper is to compare the chemical and biological properties of these Solenopsis venoms in order to possibly determine what is responsible for their different dermatological effects.

\section{Materials and Methods}

Venom was collected from major or media workers employing a previously described method (Blum et al. 1958). The chemical and biological properties of $S$. xyloni venom were studied by procedures described elsewhere (Blum et al. 1958; Blum and Callahan 1960). A crystalline derivative of the main component in $S . x y$ loni venom was prepared from an ether extract of 450 poison glands dissected from major workers. The derivative was isolated by the method of Blum and Callahan (1960).

The dermatological effects of the sting of $S . x y l o n i$ to human beings were studied by observing reactions at sting sites.

\section{Results and Discussion}

The chemical properties of the venom of $S$. xyloni parallel those of the venom of $S$. saevissima in nearly all respects. Like the venom of $S$. xyloni, the venomous secretion of $S$. saevissima consists of an alkaline two-phase system in which the suspended droplets represent the minor phase (Blum et al. 1958). The main constituent in the venom of $S . x y l o n i$ is an amine which is chemically comparable to the amine isolated from the venom of $S$. saevissima (Adrouny et al. I959; Blum and Callahan 1960). The infrared spectrum of the venom of $S$. saevissima is virtually superimposable on the spectrum of the venom of $S . x y l o n i$ and it is probable that the amine constituents which these

\footnotetext{
${ }^{1}$ Department of Entomology, Louisiana State University.

${ }^{2}$ Department of Entomology, Louisiana State University. Present Address: Louisville General Hospital, Louisville, Kentucky.

${ }^{3}$ Department of Agricultural Chemistry and Biochemistry, Louisiana State University.
} 
spectra represent are very similar. On the other hand, whereas the venom of $S$. saevissima contains two rhodamine-complexing minor components, the venom of $S$. xyloni contains only one.

The chemical similarities of the two venoms are paralled by their biological properties. The venomous principles of $S$. xyloni exhibit the same antimycotic and antibacterial activities as are found in the venom of $S$. saevissima (Blum et al. 1958). The pronounced hemolytic effect and insecticidal activity of $S$. xyloni venom compare to these same properties in the venom of $S$. saevissima (Adrouny et al. I959; Blum et al. 1958). Thus the venoms of both of these fire ants feature the same broad-spectrum activity against diverse types of cells.

The skin responses of human beings to the stings of these two fire ants are similar only during the first few hours, both being characterized by an immediate flare followed by a wheal. However, whereas the sting of $S$. saevissima is always characterized by an umbilicated pustule at the sting site (Caro et al. I957), we have found that the response to the sting of $S . x y$ loni seldom results in more than a mild prurience. In the few cases where minute pustules were observed, they were on individuals who were quite sensitive to the sting of S. saevissima. At least three explanations seem possible: ( I) minor structural modifications of the necrotoxin in the venom of $S$. saevissima are associated with a large increase in necrotoxicity when compared to its counterpart in the venom of $S$. xyloni, (2) the concentration of the necrotoxin in the venom of $S$. saevissima is greater than its counterpart in the venom of $S . x y l o n i$, (3) the minor components contribute to the necrotoxic action of the venom. These hypotheses remain to be determined experimentally.

\section{References Cited}

Adrouny, G. A., V. J. Derbes, and R. C. Jung.

1959. Isolation of a hemolytic component of fire ant venom. Science $130: 449$.

Blum, M. S. and P. S. Callahan.

1960. Chemical and biological properties of the venom of the imported fire ant (Solenopsis saevissima var. richteri Forel) and the isolation of the insecticidal component. XI Int. Kongr. Ent., Vienna. $3: 290-293$.

Blum, M. S., J. R. Walker, P. S. Callahan, and A. F. Novak.

1958. Chemical, insecticidal and antibiotic properties of fire ant venom. Science $128: 306-307$.

Caro, M. R., V. J. Derbes, and R. Jung.

1957. Skin responses to the sting of the imported fire ant (Solenopsis saevissima). A. M. A. Arch. Dermotol. 75:475-488. 

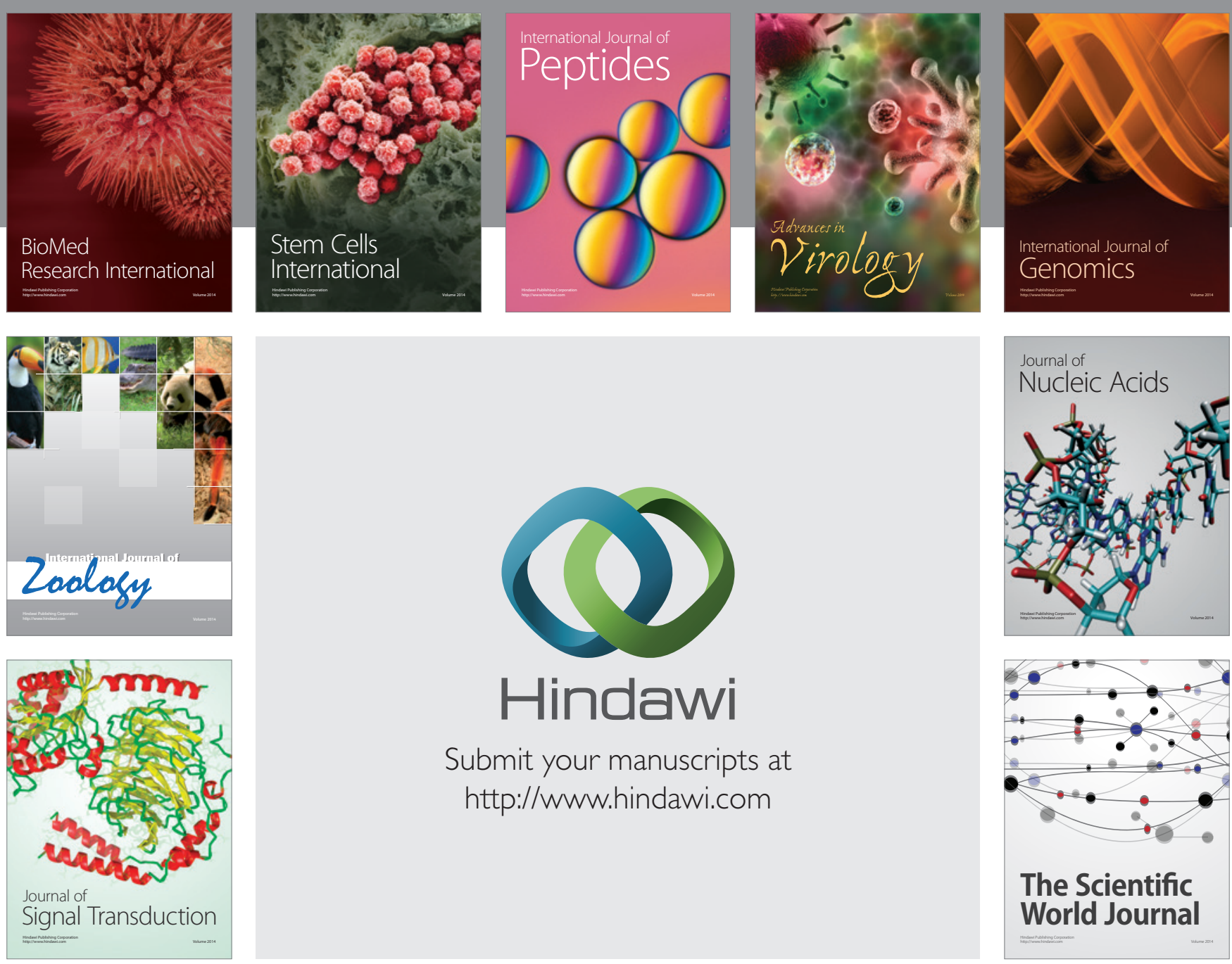

Submit your manuscripts at

http://www.hindawi.com
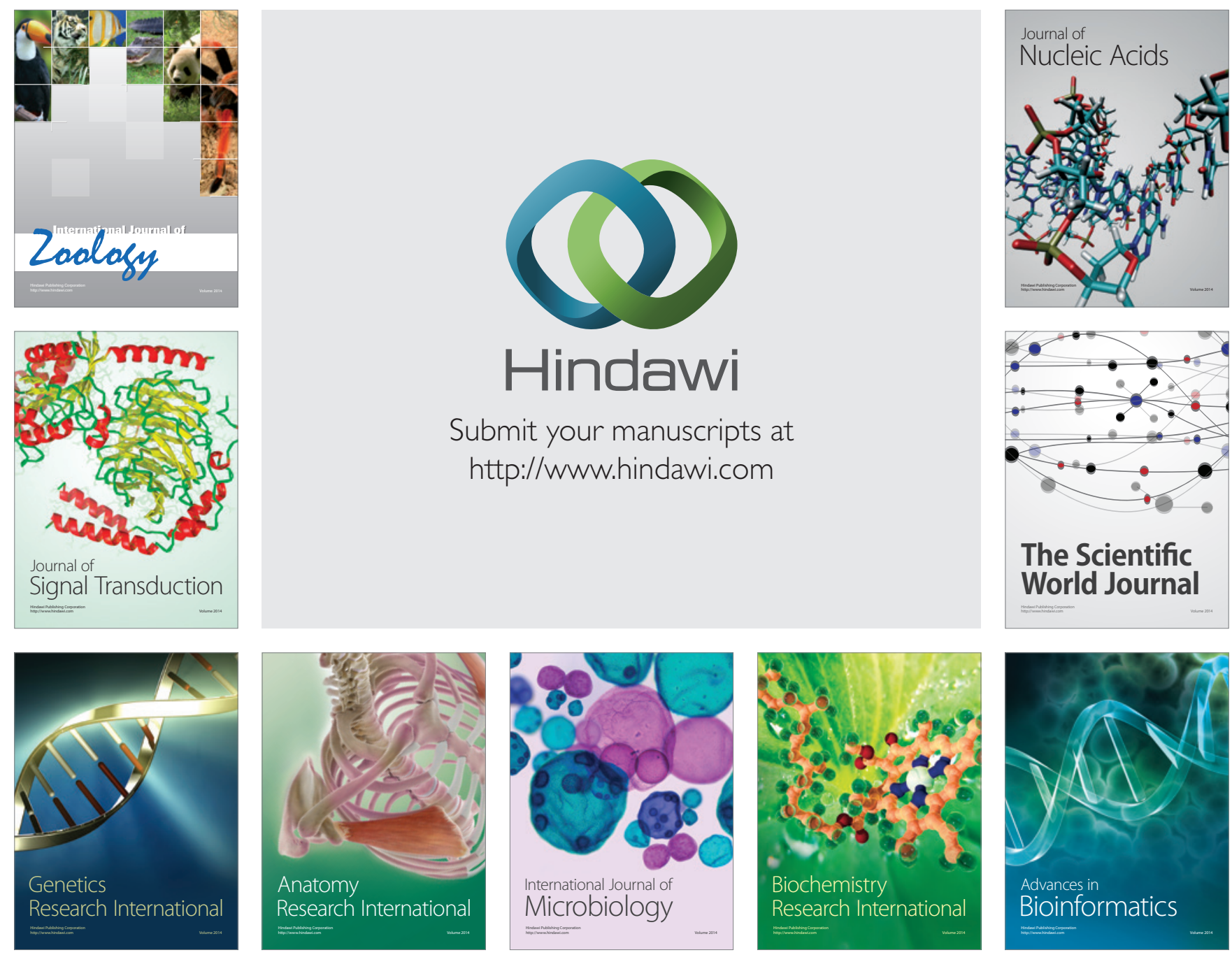

The Scientific World Journal
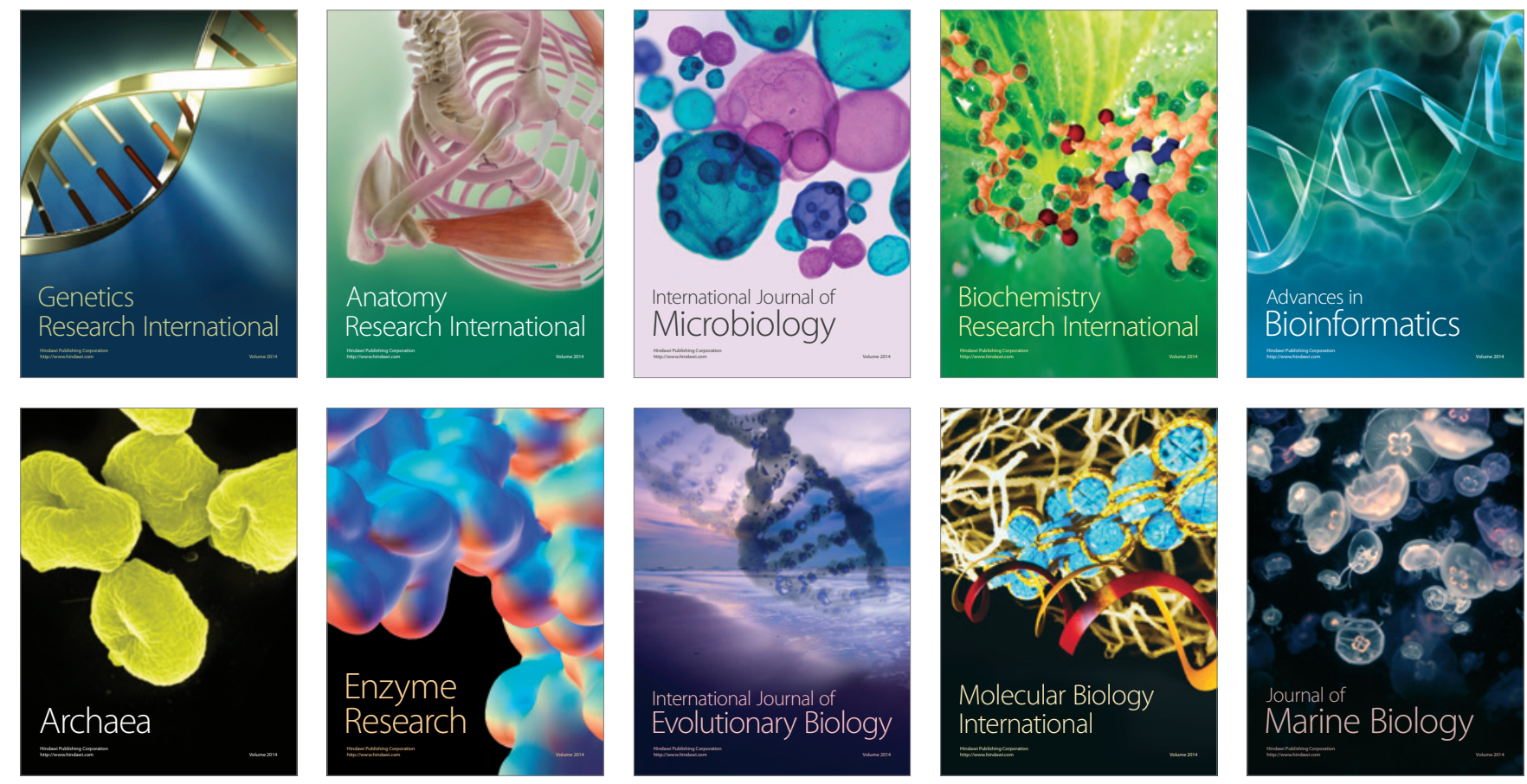